\title{
Effect of Titanium Dioxide Nanogel Surface Charges and Particle Size on Anti-Corrosion Performances of Epoxy Coatings
}

\author{
Ayman M. Atta ${ }^{1,2, *}$, Hamad A. Al-Lohedan ${ }^{1}$, Ashraf M. El-saeed ${ }^{2}$, Ahmed M. Tawfeek ${ }^{3}$ and \\ Mohamed H. Wahby \\ ${ }^{1}$ Chemistry Department, College of Science, King Saud University, Riyadh 11451, Saudi Arabia. \\ ${ }^{2}$ Petroleum application department, Egyptian petroleum research institute, Nasr city 11727, Cairo, \\ Egypt. \\ ${ }^{3}$ College of Science, King Saud University, Riyadh 11451, Saudi Arabia. \\ *E-mail: khaled_00atta@yahoo.com
}

doi: $10.20964 / 2017.02 .30$

Received: 3 November 2016 / Accepted: 11 December 2016 / Published: 30 December 2016

\begin{abstract}
The relationship between surface charges and particle sizes of nanomaterials and their effects on the anticorrosion performance of epoxy organic coatings are not previously reported. Herein, the interfacial potential and size dependent of titanium dioxide $\left(\mathrm{TiO}_{2}\right)$ nanogel composite is investigated by changing the particle charges. In this respect commercially available $\mathrm{TiO}_{2}$ nanoparticles are used as core to form nanogel composites based on 3-acrylamidopropyl) trimethylammonium chloride (APTAC) using radical crosslinking free surfactants solution polymerization. The surface charges of nanogel composites were changed by using co-monomer with APTAC such as acrylic acid (AA), N-isopropyl acrylamide (NIPAm) and 2-acrylamido-2-metylpropane sulfonate sodium salt (AMPS-Na). The particle size, surface morphology and thermal stability of $\mathrm{TiO}_{2}$ nanogel composite were determined. The surface charges and their variation with $\mathrm{pH}$ of $\mathrm{TiO}_{2}$ aqueous nanogel composite solutions were investigated. $\mathrm{TiO}_{2}$ nanogel composites were embedded in epoxy coatings with different concentrations to investigate the effect of their surface charges, particle size and dispersability on anticorrosion performances of epoxy coatings in aqueous salt solutions.
\end{abstract}

Keywords: corrosion; $\mathrm{TiO}_{2}$ nanogel composite; salt spray; epoxy organic coatings; steel.

\section{FULL TEXT}

(C) 2017 The Authors. Published by ESG (www.electrochemsci.org). This article is an open access article distributed under the terms and conditions of the Creative Commons Attribution license (http://creativecommons.org/licenses/by/4.0/). 